\title{
Vacuum-assisted Closure in Integration of Skin Graft Over Scalp Wounds: A Randomised Control Trial
}

\author{
Abdul Malik Mujahid, Farrukh Aslam Khalid, Noor Ali, Yawar Sajjad, Husnain Khan and Moazzam Nazeer Tarar \\ Department of Plastic Surgery, Jinnah Burn and Reconstructive Surgery Center / Allama Iqbal Medical College Lahore, Pakistan
}

\begin{abstract}
Objective: To compare outcome of split thickness graft with and without vacuum-assisted closure over the scalp soft tissue defects in terms of graft take and complications.

Study Design: Randomised controlled trial.

Place and Duration of Study: Department of Plastic Surgery, Jinnah Burns and Reconstructive Surgery Centre, Lahore, from June 2017 to June 2018.

Methodology: Patients with scalp soft tissue defects were recruited for the study. Patients with history of poly trauma, hypertension and diabetes mellitus were excluded. Patients were randomly divided into two groups by balloting lottery method. In group A, simple dressing were done after split thickness skin graft; and into group B, VAC dressing was applied after split thickness skin graft. Outcome variables (graft take and complications rate at recipient site) were assessed clinically at 2 weeks and analysed by Chi-square test with p-value $\leq 0.05$ was taken as significant.

Results: Mean age of 120 patients was $33.44 \pm 14.65$ years. Graft take was seen in $24(40.0 \%)$ patients in group A and in $56(93.3 \%)$ patients in group $B(p=0.0001)$. Seroma was recorded in eight $(13.3 \%)$ in group A (simple dressing) patients and one patient $(1.67 \%)$ in group B (VAC dressing, $p=0.015)$, hematoma was seen in $04(6.67 \%)$ versus $0(0.0 \%)$, respectively $(p=0.042)$ and graft edge dehiscence in $03(5.0 \%)$ versus $0(0.0 \%)$, respectively $(p=0.079)$.

Conclusion: Outcome of split skin graft over scalp soft tissue defects with VAC dressing is better than simple dressing in terms of graft take and complications rate.
\end{abstract}

Key Words: Split thickness graft, Vacuum-assisted closure, Seroma, Scalp soft tissue defect.

How to cite this article: Mujahid AM, Khalid FA, Ali N, Sajjad Y, Khan H, Tarar MN. Role of vacuum-assisted closure in integration of skin graft over scalp wounds: A randomized control trial. J Coll Physicians Surg Pak 2020; 30(2):163-167.

\section{INTRODUCTION}

Scalp defects may result from trauma, thermal or electrical burns, resection of tumors, infections or congenital lesions. A reconstructive "ladder" is followed for scalp and calvarial reconstruction. 1 A broad armamentarium of reconstructive options exists for the treatment of scalp defects including skin grafts, tissue expansions, local flaps, or free-tissue transfers. ${ }^{2,3}$

Skin grafting is an excellent option, if the defect does not involve the pericranium (periosteal) plane. ${ }^{4}$ It is a simple and reliable option with minimum donor site morbidity, provided the wound bed is well vascularised. The integration (adherence) of skin graft is influenced by diverse factors and occurs within 24-72 hours after grafting, is known as the key point for the long-term success of grafting. ${ }^{5}$ Therefore, it is important that the graft is immobilised at that stage. Healthy vascularised surface is usually required for adequate skin graft-take. Other factors that can also hinder graft-take at that stage

Correspondence to: Dr. Abdul Malik Mujahid, Jinnah Burn and Reconstructive Surgery Center, Lahore, Pakistan

E-mail: Iqbalian_127@yahoo.com

Received: May 21, 2019; Revised: December 23, 2019;

Accepted: December 27, 2019 include hematoma or seroma at the recipient site and wound infection.

Modern wound-healing techniques include different types of moist dressings and topical agents, although only a few of these treatments have convincingly been shown to give higher rates of wound healing as compared to traditional wound dressings. 6 Over the past 50 years, clinicians have described how certain wounds respond to sub-atmospheric pressure used within a closed dynamic delivery system. ${ }^{7}$ The vacuum-assisted closure device has revolutionised wound care since its first introduction in 1997.8 This technique, developed by Argenta and Morykwas to expedite wound healing by secondary intention, is based on the principles of controlled negative pressure wound therapy (NPWT) application, often called topical negative pressure (TNP). 8,9 It is effective for treating acute, chronic, and infected wounds. It expedites wound preparation for skin grafting, and promotes subsequent graft adherence. It has been reported to increase local vascularity with formation of granulation tissue, reduction in interstitial edema and bacterial contamination, which eventually enhance the skin graft-take. 10,11

During the past decade, NPWT has become a common treatment of acute and chronic wounds. It has revolu- 
tionised the management of open wounds. The granulation tissue formed with this technique is high of quality, rich in capillaries, and suitable for skin graft. Many surgeons have adopted the use of NPWT as a bolster dressing for split-thickness skin grafts (STSG) and full-thickness skin grafts.12 Studies have shown improved graft survival and epithelialisation with NPWT bolster, as well as decreased numbers in repeat STSG procedures. So, there is improvement in graft incorporation particularly in large or irregularly shaped wounds. Although studies have suggested negative pressure settings for wound healing but similar settings may not be optimal when used over skin grafts. ${ }^{13}$ NPWT yieldes significantly lower nursing staff costs, reduces risk of cross infection, and more comfortable for the patients than treatment with other wound dressings. 14

In a study by Saaiq et al., marked differences were found in favour of the VAC therapy group with respect to various wound management outcome measures studied. i.e. graft-take ( $90 \%$ of VAC therapy group vs. $18 \%$ of controls), wound healing time (2 weeks post-grafting in $90 \%$ of VAC therapy group vs. $18 \%$ of controls), need for regrafting (none among VAC therapy group vs. $8 \%$ of controls) and duration of hospital stay (less than 3 weeks in $90 \%$ of VAC therapy group vs. $18 \%$ of controls). ${ }^{15}$ Graft loss and need for re-grafting was zero\% in VAC therapy group vs. $8 \%$ in traditional gauze dressing group.

The objective of this research was to determine the outcome of STSG with or without VAC in terms of grafttake and complications rate. The rationale was that the outcome of the study would change the clinical practice of the department. Published data in local settings was limited on this aspect, so this study will be a good addition.

\section{METHODOLOGY}

A randomised control trial was conducted from $16^{\text {th }}$ June 2017 to $15^{\text {th }}$ June 2018 at the Department of Plastic Surgery, Jinnah Burns \& Reconstructive Surgery Center. After the approval from Ethical Committee of Hospital,
120 patients (sample size calculated using win-pepiver 11.15 with $80 \%$ power of test, $2.5 \%$ level of significance) with scalp soft tissue defects were recruited for study. Patient having soft tissue defect of more than $6 \mathrm{~cm}$ over scalp, after trauma, burn or tumor excision, with age between 5 to 65 years of either gender were included in the study. The sampling was non-probability, consecutive sampling. Patients with history of polytrauma, hypertension and diabetes mellitus and wounds more than four weeks were excluded from study.

Subjects were randomly divided into two groups (60 in each group) by using balloting method by researcher; group A without VAC dressing after split thickness skin graft and group B with VAC dressing after split thickness skin graft. Informed consent was obtained from them. All the patients were photographed and baseline assessment was done before starting the treatment. The wound was debrided and washed with normal saline under general anesthesia. After the split-skin graft secured with staplers, the control group received the conventional dressing consisting of a vaseline gauze, cotton pads and cotton bandage. In the study group, VAC dressing was placed on the graft with continuous pressure of $50 \mathrm{~mm}$ of $\mathrm{Hg}$ for 3 days. The dressings were continually observed by the nursing staff and resident doctor and suction was assured by visualising the collapsed foam and absence of gushing sound. The grafts were inspected on fourth postoperative day after which, negative pressure dressing was discontinued in group B. Patients were discharged after second dressing change and were followed up for a total of three weeks.

Outcome variables (graft-take and complications) were assessed clinically at 2 weeks by three consultant plastic surgeons. Data was entered and analysed in S.P.S.S. version 17. Mean and standard deviations were calculated for numerical variables like age, area of scalp injury, and duration of injury. Frequencies and percentages were calculated for nominal/qualitative variables like gender, outcome (graft-take and complications). Both groups were compared by Chi-square test; and $p$-value $<0.05$ was taken as significant.

Table I: Demographic and clinical characteristics of subjects.

\begin{tabular}{|c|c|c|c|c|c|c|}
\hline & \multicolumn{2}{|c|}{ Group A $(n=60)$} & \multicolumn{2}{|c|}{ Group B $(n=60)$} & \multicolumn{2}{|c|}{ Total $(n=120)$} \\
\hline & Frequency & Percentage & Frequency & Percentage & Frequency & Percentage \\
\hline \multicolumn{7}{|l|}{ Age (years) } \\
\hline $5-35$ & 37 & 61.7 & 35 & 58.3 & 72 & 60.0 \\
\hline $36-65$ & 23 & 38.3 & 25 & 41.7 & 48 & 40.0 \\
\hline Mean \pm SD & $32.53 \pm 14.61$ & & $34.35 \pm 14.76$ & & $33.44 \pm 14.65$ & \\
\hline \multicolumn{7}{|c|}{ Duration of injury } \\
\hline $1-2$ weeks & 39 & 65.0 & 38 & 63.3 & 77 & 64.7 \\
\hline 3-4 weeks & 21 & 35.0 & 22 & 36.7 & 43 & 35.3 \\
\hline Mean $\pm S D$ & $2.68 \pm 0.77$ & & $2.71 \pm 0.78$ & & $2.69 \pm 0.77$ & \\
\hline \multicolumn{7}{|l|}{ Size of injury } \\
\hline $7-10 \mathrm{~cm}$ & 42 & 70.0 & 40 & 66.7 & 82 & 68.3 \\
\hline$>10 \mathrm{~cm}$ & 18 & 30.0 & 20 & 33.3 & 38 & 31.7 \\
\hline Mean $\pm S D$ & $9.08 \pm 2.13$ & & $9.12 \pm 2.18$ & & $9.10 \pm 2.16$ & \\
\hline
\end{tabular}


Table II: Frequency of graft take and complications of split thickness graft with and without vacuum-assisted closure in scalp wounds ( $\mathrm{n}=120$ ).

\begin{tabular}{|c|c|c|c|c|c|}
\hline & \multicolumn{2}{|c|}{ Group A $(n=60)$} & \multicolumn{2}{|c|}{ Group B $(n=60)$} & \multirow[t]{2}{*}{$p$-value } \\
\hline & Frequency & Percentage & Frequency & Percentage & \\
\hline \multicolumn{6}{|c|}{ Graft take } \\
\hline Yes & 24 & 40.0 & 56 & 93.3 & \multirow[t]{2}{*}{0.0001} \\
\hline No & 36 & 60.0 & 04 & 6.7 & \\
\hline \multicolumn{6}{|c|}{ Complications } \\
\hline \multicolumn{6}{|c|}{ Seroma } \\
\hline Yes & 08 & 13.3 & 01 & 1.67 & \multirow[t]{2}{*}{0.015} \\
\hline No & 52 & 86.7 & 59 & 98.3 & \\
\hline \multicolumn{6}{|c|}{ Hematoma } \\
\hline Yes & 04 & 6.67 & 00 & 0.0 & \multirow[t]{2}{*}{0.042} \\
\hline No & 56 & 93.3 & 60 & 100.0 & \\
\hline \multicolumn{6}{|c|}{ Graft edges dehiscence } \\
\hline Yes & 03 & 5.0 & 00 & 0.0 & \multirow[t]{2}{*}{0.079} \\
\hline No & 57 & 95.0 & 60 & 100.0 & \\
\hline
\end{tabular}

\section{RESULTS}

A total 120 patients were included in the study. Subjects' mean age was $33.44 \pm 14.65$ years with mean duration of injury as $2.69 \pm 0.77$ weeks. The mean size of injury was $9.10 \pm 2.16 \mathrm{~cm}$ (Table I). The graft-take in group A (simple dressing) was seen in $24(40.0 \%)$ patients and in group B (VAC dressing) was seen in 56 (93.3\%) patients with $\mathrm{p}$-value $=0.0001$. The complications, i.e. seroma, was recorded in $08(13.3 \%)$ patients in group A (simple dressing) while $01(1.67 \%)$ patients in group B (VAC dressing) $(p=0.015)$, hematoma was seen in $04(6.67 \%)$ versus $0(0.0 \%)$, respectively $(p=0.042)$ and graft edges dehiscence in $03(5.0 \%)$ versus $0(0.0 \%)$, respectively (p-0.079) (Table II).

\section{DISCUSSION}

Negative pressure wound therapy is a popular treatment for the management of acute and chronic wounds. It is an established option in the bolstering of STSG at a pressure setting as low as $50 \mathrm{mmHg}$ without compromise to STSG incorporation. ${ }^{13}$ Lower pressure settings may create potential benefits to patients with less pain and less secondary skin reaction at the STSG cutaneous borders. These findings follow the physiologic rationale that any pressure above normal capillary pressure, approximately $25 \mathrm{mmHg}$, should improve angiogenesis and epithelialisation. ${ }^{13}$

Several postulates suggest that negative-pressure dressings may improve graft survival. First, an important aspect to successful graft-take is maintaining good apposition between the graft and the wound surface. Continuous negative-pressure dressings provide a uniform distribution of pressure and apposition between the graft and the wound bed in most cases. Second, the negative-pressure dressing provides continuous removal of wound fluid, which prevents the accumulation of hematoma or seroma while maintaining graft-to-wound apposition. Third, desiccation is detrimental to wound healing and is reduced with the occlusive nature of the
VAC dressing, in which a moist environment is maintained. Last, the VAC has been associated with lower bacterial counts at wound sites and this reduction in the local bacterial flora may enhance graft survival. 16

Compared to the existing dressing treatment, NPWT can decrease the loss of graft due to better fixation of the graft because exudation and hematoma are easily absorbed and it is more comfortable than tie over bolster dressing because of its easiness to apply on wound. As a result, the length of treatment on operating room can be reduced. The patient satisfaction rate increases because of increased patient mobility with portable NPWT device. If the skin graft is dressed with conventional bolster dressing, the failure rate is generally reported to range from $15 \%$ to $30 \%$ compared with $2 \%$ with negative pressure wound therapy. ${ }^{17}$

Encouraging results in terms of rates of healing have been reported in the literature but there is a relative paucity of randomised controlled trials with significant numbers to substantiate the findings. Mullner et al. prospectively studied 45 patients with various wounds to which the VAC was applied. There was no control group and again the recommendations on settings for the VAC were based on anecdotal evidence but $80 \%$ reduction in size was found during the period of study in 12 of the 17 pressure sores. 18 In a study, a total of 40 split-skin grafts were put on 30 patients. Twenty-one of them received negative pressure dressing (NPD) and 19 served as controls. Final graft-take at nine days in the study group ranged from 90 to 100 per cent with an average of 96.7 $\pm 3.55 \%$. The control group showed a graft-take ranging between 70 and 100 percent with an average graft-take of $87.5 \pm 8.73 \%$. Each of these differences was found to be statistically significant $(p<0.001) .19$

In another study, the authors reported a randomised controlled trial comparing the efficacy of the standard gauze sealed with an occlusive dressing and wall suction (GSUC) vs. the VAC in securing STSG. A prospective, randomised, controlled trial was conducted in 
157 wounds in 104 patients requiring STSG from August 2009 to July 2012. All wounds were randomised to VAC or GSUC treatment and assessed for skin graft adherence/take. At postoperative day 4 or 5, NPWT was discontinued, and the size of the graft and any non-adherent areas were measured and recorded. Concomitant comorbidities, wound location, etiology, study failures, and re-operation rates were also reviewed. Out of 157 wounds, 77 and 80 wounds were randomised to the GSUC and VAC study arms, respectively. Patient demographics were similar in both groups in terms of age, sex, comorbidities, etiology, and wound location. In 157 wounds, 64 of 80 wounds in the GSUC group, and 60 of 77 wounds in the VAC group had full take of the skin graft by postoperative day 4 or $5(p=0.80)$. The mean percent graft-take in the GSUC group was $96.12 \%$ vs. $96.21 \%$ in the VAC arm $(p=0.98) .20$ This study signifies a good skin graft-take with negative pressureassisted dressings, which similar to the VAC dressing group $(96.21 \%$ vs. $93.33 \%)$.

This study was conducted and the results were compared to the study by Saaiq et al., that showed marked differences in favour of the VAC therapy group with respect to the various wound management outcome measures studied, i.e. graft-take (greater than 95\% grafttake in $90 \%$ of VAC therapy group vs. $18 \%$ of controls). In this study, the graft-take in group A (simple dressing) was seen in $16(26.67 \%)$ patients and in group B (VAC dressing) was seen in 56 (93.33\%) patients ( $p=0.0001$. The complications, i.e. seroma, was recorded in 08 $(13.3 \%)$ in group $A$ (simple dressing) patients while 01 $(1.67 \%)$ in group $B$ (VAC dressing) patients $(p=0.0001)$, hematoma was seen in $04(6.67 \%)$ versus $0(0.0 \%)$, respectively $(p=0.015)$ and graft edges dehiscence in $03(96.67 \%)$ versus $0(0.0 \%)$, respectively $(p=0.079)$.

\section{CONCLUSION}

Outcome of split skin graft over scalp wounds with VAC dressing was better than without VAC in terms of graft take and low complication rate. So, VAC dressing with split thickness skin graft in scalp wounds may be opted to promote better outcome and reducing the morbidity of particular patients.

\section{ETHICAL APPROVAL:}

The study was approved by Ethical Committee of Jinnah Burns \& Reconstructive Surgery Centre, Lahore.

\section{PATIENTS' CONSENTS:}

Informed consent were obtained from all patients.

\section{CONFLICT OF INTEREST:}

Authors have no financial or personal interests with any people or organisation that would influence this work.

\section{AUTHORS' CONTRIBUTION:}

AMM, FAK, NA. Contributed in design of work and data collection.

YS, HK: Contributed in the data analysis, results, discussion and drafting of work.

MNT: Contributed in final review and approval of article.

\section{REFERENCES}

1. Lin SJ, Hanasono MM, Skoracki RJ. Scalp and calvarial reconstruction. Semin Plast Surg 2008; 22:281-93.

2. Newman MI, Hanasono MM, Disa JJ, Cordeiro PG, Mehrara BJ. Scalp reconstruction: A 15-year experience. Ann Plast Surg 2004; 52:501-6.

3. Molnar JA, DeFranzo AJ, Marks MW. Single-stage approach to skin grafting the exposed skull. Plast Reconstr Surg 2000; 105:174-7.

4. Cherubino M, Taibi D, Scamoni S, Maggiulli F, Giovanna D, Dibartolo $\mathrm{R}$, et al. A new algorithm for the surgical management of defects of the scalp. ISRN Plastic Surgery 2013; 2013:916071.

5. Seung BP, Kun YS, Hong SJ, Jin KS, Seong YL. Vacuumassisted closure therapy in split-thickness skin graft on the wound on the contours of the body. J Wound Manag Res 2017; 13:35-9.

6. Seidel $D$, Mathes $T$, Lefering $R$, Storck $M$, Lawall $H$, Neugebauer EA. Negative pressure wound therapy versus standard wound care in chronic diabetic foot wounds: Study protocol for a randomized controlled trial. Trials 2014; 15:334.

7. Jacobs S, Simhaee DA, Marsano A, Fomovsky GM, Niedt G, Wu JK. Efficacy and mechanisms of vacuum-assisted closure (VAC) therapy in promoting wound healing: A rodent model. J Plast Reconstr Aesthet Surg 2009; 62:1331-8.

8. Morykwas MJ, Argenta LC, Shelton-Brown EI, McGuirt W. Vacuum-assisted closure: A new method for wound control and treatment: Animal studies and basic foundation. Ann Plast Surg 1997; 38:553-62.

9. Argenta LC, Morykwas MJ. Vacuum-assisted closure: A new method for wound control and treatment: clinical experience. Ann Plast Surg 1997; 38:563-76.

10. Saxena V, Hwang CW, Huang S, Eichbaum Q, Ingber D, Orgill DP. Vacuum-assisted closure: Microdeformations of wounds and cell proliferation. Plast Reconstr Surg 2004; 114:1086-96.

11. V.A.C. Therapy Clinical Guidelines: A Reference Source for Clinicians. http://www.kci1.com/KCl1/vactherapyformsand brochures. Updated December 2012. [Accessed on October 23, 2013].

12. Issac AL, Rse J, Armstrong DG. Mechanically powered negative pressure wound therapy as a bolster for skin grafting. Plast Reconstr Surg Glob Open 2014; 2:e103.

13. Evangelista MS, Kim EK, Evans GR, Wirth GA. Management of skin grafts using negative pressure therapy: The effect of varied pressure on skin graft incorporation. Wounds 2013; 25:89-93.

14. Chiummariello S, Del Torto G, lera M, Arleo S, Alfano C. Pressure dressing in split thickness skin grafts: experience with an alternative method. Wounds 2013; 25:324-7.

15. Saaiq M, Din H, Khan MI, Chaudhery SM. Vacuum-assisted closure therapy as a pretreatment for split thickness skin grafts. J Coll Physicians Surg Pak 2010; 20:675-9. 
16. Mohsin M, Zargar HR, Wani AH, Zaroo MI, Baba PUF, Bashir SA, et al. Role of customised negative-pressure wound therapy in the integration of split-thickness skin grafts: A randomised control study. Indian J Plast Surg 2017; 50:43-9.

17. Lee DH, Kim YJ. Negative pressure wound therapy applied to a meshed split-thickness skin graft. Arch Reconstr Microsurg 2016; 25:29-36.

18. Mullner T. The use of negative pressure to promote the healing of tissue defects: A clinical trial using the vacuum sealing technique. Br J Plast Surg 1997; 50:194-9.
19. Petkar KS, Dhanraj P, Kingsly PM, Sreekar H, Lakshmanarao A, Lamba S. A prospective randomized controlled trial comparing negative pressure dressing and conventional dressing methods on split-thickness skin grafts in burned patients. Burns 2011; 37:925-9.

20. Nguyen TQ, Franczyk M, Lee JC, Greives MR, O'Connor A, Gottlieb LJ. Prospective randomized controlled trial comparing two methods of securing skin grafts using negative pressure wound therapy: Vacuum-assisted closure and gauze suction. J Burn Care Res 2015; 36:324-8.

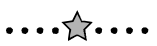

